\title{
CASE STUDIES CAN SUPPORT DEFINITIONS OF WORKPLACE INNOVATION IN PRACTICE
}

\author{
Fietje Vaas \\ TNO, The Netherlands \\ Organization for Applied \\ Scientific Research \\ Fietje.vaas@tno.nl
}

\author{
Rita Žiauberytè-Jakštienè \\ TNO, The Netherlands \\ Organization for Applied \\ Scientific Research
}

\author{
Peter R. A. Oeij \\ TNO, The Netherlands \\ Organization for Applied \\ Scientific Research
}

\begin{abstract}
About the authors
Fietje Vaas is a psychologist temporarily affiliated with TNO, The Netherlands Organization for Applied Scientific Research. Currently she is working on topics such as innovation of work organization and the management and employment relations of private and public organizations.

Rita Žiauberytè-Jakštienè is a junior researcher at TNO, The Netherlands Organization for Applied Scientific Research. Formerly she has been a recruitment consultant in personnel selection agencies in Lithuania. Her research interests include social innovation, workplace innovation, and goal-setting topics.
\end{abstract}

Peter R. A. Oeij is a senior researcher/consultant at TNO, The Netherlands Organization for Applied Scientific Research (Leiden, The Netherlands). The main topics of his work are innovation management, workplace innovation, social innovation, productivity, flexibility, working smarter and team work.

\begin{abstract}
Many practitioners find it problematic to understand and describe workplace innovation (WPI). Whereas there are well-known definitions of WPI, these remain highly abstract. We argue that, for practitioners, case examples of WPI best practices can be a valuable addition to these definitions. In this respect, based on our practical experience with WPI and the cases that resulted from the Eurofound study (Eurofound, 2015), we propose the following criteria for a case to be a good example for practical purposes. First, the company that serves as a case should have implemented good workplace innovation practices that have resulted in or theoretically promise to result in positive outcomes for the organization and for the quality of work. Second, the case description has to provide actionable information about the WPI practices. Third, the narrative of the case has to be inspiring and provide possibilities for stakeholders to identify with it. We present a number of the Eurofound cases that are informative and inspiring for practitioners while also presenting actionable information.
\end{abstract}

\section{Definitions of workplace innovation are not very actionable}

Practitioners interested in implementing workplace innovation (WPI) practices are in dire need of clear definitions of the concept. A recent study on WPI and its indicators conducted by the European Commission (2014), in the frame of the European Innovation Scoreboard (EIS) 20132014 project, identified 8 different definitions of WPI (p.13 and 14). Whereas they differ to a certain extent, all of these definitions conceptualize WPI as being a field or fields of action, a participative process and a win-win outcome for the organization and employees. Moreover, some provide specific examples of WPI practices, such as: participative job design, selforganised teams and continuous improvement. 
In the table below, we provide a selection of four of these definitions that showcase the elements mentioned above.

\section{Table 1. Workplace Innovation Definitions}

\begin{tabular}{|c|c|}
\hline Source & Definition \\
\hline $\begin{array}{l}\text { European } \\
\text { Commission } \\
(2014)\end{array}$ & $\begin{array}{l}\text { "Those innovations aim at improving staff motivation and working conditions, thereby enhancing } \\
\text { labour productivity, organizational performance, innovation capability, reactivity to market changes } \\
\text { and consequently business competitiveness." (p. 13) }\end{array}$ \\
\hline $\begin{array}{l}\text { Dortmund } \\
\text { Brussels } \\
\text { position paper } \\
\text { on WPI } \\
\text { (2012) }\end{array}$ & $\begin{array}{l}\text { "Workplace Innovation is defined as a social process which shapes work organization and working } \\
\text { life, combining their human, organizational and technological dimensions. } \\
\text { Examples include participative job design, self-organized teams, continuous improvement, high } \\
\text { involvement innovation and employee involvement in corporate decision making. Such } \\
\text { interventions are highly participatory, integrating the } \\
\text { knowledge, experience and creativity of management and employees at all levels of the } \\
\text { organization in a process of cocreation and co-design. This simultaneously results in improved } \\
\text { organizational performance and enhanced quality of working life....." (p. 2) }\end{array}$ \\
\hline $\begin{array}{l}\text { Eurofound } \\
\text { (2015) }\end{array}$ & $\begin{array}{l}\text { "High performance work practices or innovations in work organization are defined as deliberate } \\
\text { changes that can affect how employees undertake their job and/or their broader experience of } \\
\text { work and refer to any element of people management" (p. 11) }\end{array}$ \\
\hline $\begin{array}{l}\text { Pot, Dhondt, and } \\
\text { Oeij (2012) }\end{array}$ & $\begin{array}{l}\text { "Workplace innovations are strategically induced and participatory adopted changes in an } \\
\text { organization's practice of managing, organizing and deploying human and non-human resources } \\
\text { that lead to simultaneously improved organizational performance and improved quality of working } \\
\text { life." (p. 262). }\end{array}$ \\
\hline
\end{tabular}

Whereas these definitions are clear, most remain relatively abstract. This can be helpful given that implementing WPI successfully is highly dependent on the situation, the context and the history of any given organization. In this sense, the definition should leave room for local interpretation since the concept of WPI itself implies that management should not impose a blueprint of an action plan upon those involved. Employee participation in the design of WPI measures and in the implementation process is a necessary condition for real WPI (Oeij et al., 2015a; Pot, 2011; Ramstad, 2009; Totterdill \& Exton, 2014).

However, while it is inevitable from a theoretical point of view for definitions to be abstract, from a practical standpoint, more actionable (Argyris, 1996) information would be helpful. It is possible that this lack of actionable information on WPI could explain why relatively few organizations have implemented WPI practices, although they promise win-win outcomes for all involved. Indeed, we have often encountered the following questions cropping up in companies preparing to implement WPI: "What are we talking about? What changes in job design, work organization and management are we supposed to implement? Can't you give us examples of good WPI practices, so that we can understand?"

We conclude that, next to clear theoretical definitions of WPI, practitioners could benefit from examples of cases that embody good WPI practice. Therefore, the study, documentation and dissemination of cases representing best practices are very important for practitioners. ${ }^{1}$

Moreover, for researchers, it is important to know how to produce and report case studies that can lead to learning in practical situations.

In this article, we focus on the following question: what information should a case study provide to help practitioners, managers and employees in their search for concrete WPI interventions? In other words: what makes a WPI case a good example for practical purposes?

\footnotetext{
${ }^{1}$ There are two knowledge banks where many WPI-cases can be found: www.workplaceinnovation.org and EUWIN's knowledge bank: http://portal.ukwon.eu/euwin-knowledge-bank-menu-new
} 
First, based on our practical experience, we will reflect on the criteria that would render a case a good example of WPI. Second, we will use the case studies analysed and described in mini cases $^{2}$ in the Eurofound project: Workplace innovation in European companies (Oeij et al., $2015 a ; 2015 b)$ to more thoroughly explain these criteria. Note that we are not developing a case study methodology. We simply want to share our practical experience with WPI and provide a simple framework that can be used by practitioners discussing an intervention with stakeholders and by researchers when reporting a case study.

\section{What makes a case a good example of WPI practice?}

First, a case, that is a good example of WPI practice, should exhibit real, substantial WPI practices. Whereas this is a common-sense argument that might even sound trivial, we deem it important, given that, in some cases, lip service has been paid to WPI without any structural changes (see e.g. Ramstad, 2009). In other words, the case should show that workplace innovation practices have been implemented that have led to (or theoretically promise to lead to) improved company performance and improved quality of work. However, determining whether a WPI case does indeed showcase substantial WPI practices is tricky, given that WPI definitions are neither extremely detailed nor actionable in themselves. This issue also arose in the Eurofound study and was solved by asking WPI experts to assess the cases based on their theoretical knowledge and experience with WPI interventions, and to subsequently, categorise them as exhibiting high, medium or less substantial WPI practices (see the paragraph about the Eurofound study below).

Second, for a case to be a good example of WPI practice, a thorough description of the case needs to be available. Without a thorough, detailed description, the value added for practitioners in other organizations is significantly diminished. In this respect, a case description should outline the specific practices/measures/ actions/interventions initially planned to be implemented and discuss the ones that have actually been implemented. Preferably, the case description should be broken down into clear steps that could be replicated in other organizations, although they might have to be adapted to fit these other contexts. In other words, the information presented should be actionable. As Argyris (1996) suggested, attention should be paid to informing the reader on how to create - in this case - workplace innovation. That is, it should inform people in other organizational contexts what has been changed in the structure (job design, work organization, hierarchical structure) and the culture (empowerment, management, trust, HR practices) of the organization to achieve WPI.

Third, the case has to be inspiring. This means that the description really gets across the story of the change in this organization. Profound storytelling and high-quality narratives have the capacity to reveal important, real-life facts of a case (Gabriel, 2013). Preferably, the description is a narrative that gets the reader to be enthusiastic about the changes in jobs and roles, organizational structure, corporate climate, behaviour, labour relations and trust, etc. It shows the reader that the bundle of WPI practices that is, or was, implemented promise to result or have resulted in the improvement of the company's performance, sustainability and innovative capabilities as well as in providing challenging jobs and good work prospects for all employees.

One strong mechanism to provoke inspiration is identification. Positive collective narratives that people identify with can influence behaviour, cognition and emotions in a favourable way (Rappaport, 1995). Therefore, the narrative should include the possibility for various groups of

\footnotetext{
${ }^{2}$ The Eurofound website presents all the 51 mini cases: http://www.eurofound.europa.eu/surveys/2013/europeancompany-survey-2013-00
} 
readers to identify with, in the sense that they can recognize the kind of work, their position (manager, employee, employee representative, trade-unionist, user), the sector, the size of the organization and/or the cultural context. For instance, for employees, it is important that the narrative showcases employees in the case-organization who speak positively about the change process and/or the (predicted) results. Another factor that can lead to identification or, for that matter, to non-identification, is the cultural context of the case as well as national or regional labour relations. For instance, the results of a Danish case could seem so unattainable to Greek managers and employees that the case turns out to be scary instead of inspiring. The same may count for cases from different sectors. Employees of a chemical factory might think (rightly or wrongly) when hearing about practices successfully implemented in a school that: 'this will not work for us'. Therefore, it is important to embed a case in its cultural or sectorrelated context, so that a practitioner can decide whether he or she can use it in a specific organization.

\section{Figure 1. The criteria for a case study to be a good example of WPI practice}

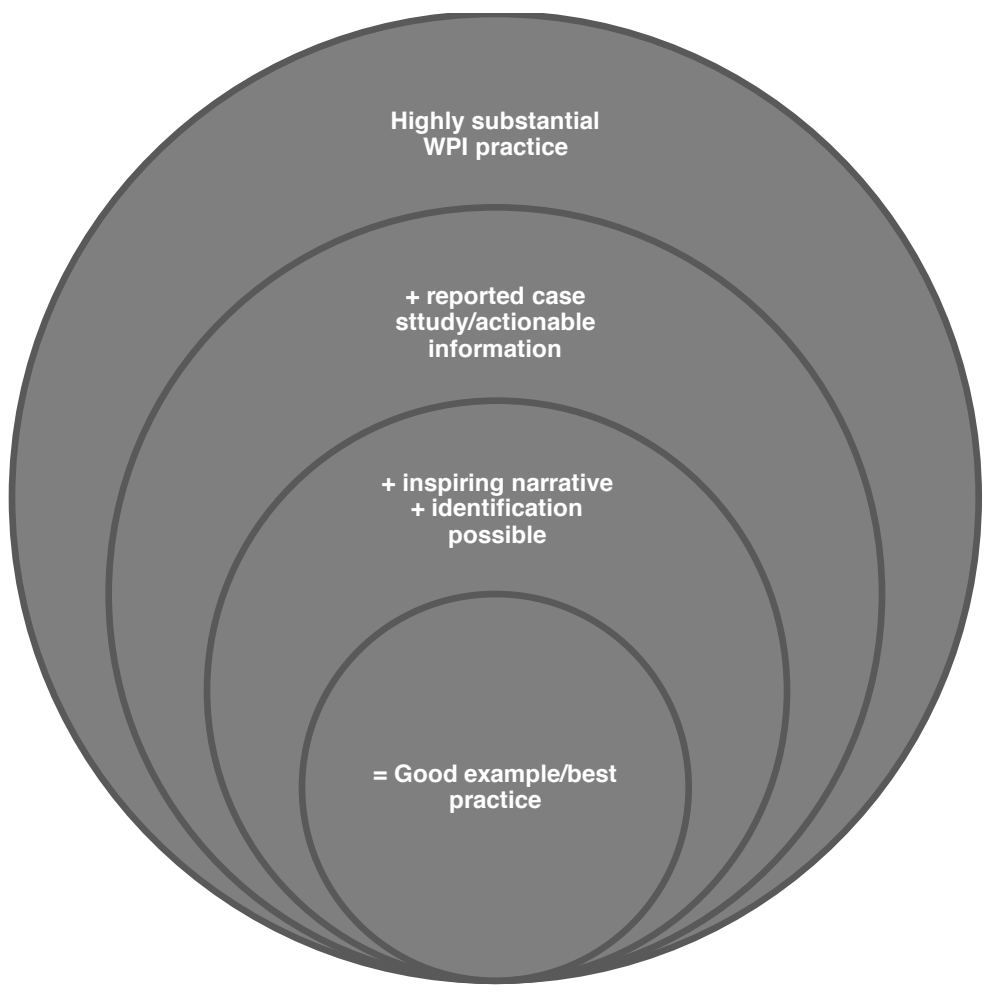

The figure above summarises the criteria that preferably should be present in a case description of WPI practices. In the next paragraphs, we will elaborate on these criteria and show how they can be applied to existing case studies. To this end, we will use the case studies described and analysed in the Eurofound study ${ }^{3}$. We will introduce that study first.

\section{The Eurofound study: A source for WPI cases}

The Eurofound study was commissioned by the European Foundation for the improvement of Living and Working Conditions (Eurofound) (Oeij et al., 2015a; 2015b). The purpose of the study was to investigate why and how companies in the European Union apply WPI. The authors of this article were involved in this study as part of a larger international research team. During 2014 - 2015, interviews were held in 51 selected companies covering ten EU member

${ }^{3}$ Also see the website: http://www.eurofound.europa.eu/surveys/2013/european-company-survey-2013-00 
states. These companies represent the $5 \%$ best scoring companies out of 30.000 companies on a workplace innovation-index in the European Company survey 2013 (Dhondt et al., 2014). Interviews were held with managers, employees and employee representatives and mini-case study reports were written.

As part of the Eurofound study, each case was assessed by three experts ${ }^{4}$. They based their assessment on theoretical notions about the types of interventions that may lead to the desired outcomes of improving the quality of working life and organizational performance. They assessed whether in each case, structural and/or cultural WPI measures, supported by HR measures were indeed implemented. All 51 cases were subsequently assigned a score from 0 to 10 based on a number of criteria representing structural (0- 4 points), cultural (0-4 points), bundled or HR supportive interventions (0-2 points). Based on the final-scores, the cases were classified as being exemplary of highly (16), medium (21) or less (14) substantial WPI practices (Oeij et al., 2015b).

\section{Cases that distinguish between substantial and less substantial WPI practices}

For a better understanding of what highly substantial and less substantial WPI practices mean, below, we will provide a description of a case with a high score and one with a low score (see Table 2). We chose to present the Danish manufacturing case because it scored the highest $(9,67$ out of 10$)$ out of all 51 cases. It received such a high score because it embodies a promising combination of structural and cultural bundles of measures integrated by an explicit vision on WPI. Moreover, the case study exhibits positive outcomes for both the organization and the workers. The Polish school was selected as an example of a case with the lowest score on WPI (2,33 out of 10). Although good practices were implemented, they were not considered to be Workplace Innovations, since they were merely IT-related measures.

In the rest of this article we will exclusively focus on the 16 cases that were qualified by the experts as having implemented highly substantial WPI practices, given that that is a core element of a case to be a good example of WPI practice. To this end, we will select cases that best embody the remaining criteria.

\footnotetext{
${ }^{4}$ The three experts discussed their individual ratings and the final score was reached via consensus.
} 


\section{The case with the highest WPI score}

DK-MANU-FABRIC-S ${ }^{5}$ [Denmark-manufacturing-making fabrics] is an international company that produces fabrics for different customer groups (retail, hotels, furniture manufacturers etc.). The headquarter of the company is in Denmark and it counts one hundred and forty-five employees there who support the manufacturing process in different European countries.

The company operates from a vision that workplace innovation is "a way to ensure renewal and the ability to offer a service that is so good that customers will chose this company over others" (Denmark_Minicase_Kvadrat, p 1/3). This company has implemented the following WPI practices: 1 . customer segment teams, 2 . autonomous and semiautonomous team work, 3. a flat hierarchy, (structural improvements according to the experts) 4. room for proposals to improve processes, products or services, 5. participative formulating of performance goals and targets, 6 . innovation meetings for product development (cultural or mixed improvements, according to the experts).

The customer segment teams are multi-disciplinary teams that serve segments of clients, such as retail or hospitals. Those employees, who have direct or indirect contact with a group of customers, work together in a team. In supporting departments, such as the Order Expedition, employees work in autonomous or semi-autonomous teams. They distribute their work themselves at a daily morning meeting. There are only three hierarchical layers: the board of managers, middle managers and employees. Every employee can make a proposal directly to the management or colleagues and, if possible, these ideas are directly implemented.

Performance goals and scores are formulated together with the employees, which leads to mutual trust building. The department for product development organises continuous innovation meetings, where creative thinking is promoted. According to the manager and the employees that were interviewed, these interventions resulted in very positive outcomes. The manager stressed that an innovative culture, knowledge sharing and autonomous, interdisciplinary teams give the company competitive advantage. Employees described working in multi-disciplinary teams as highly motivating and said they feel in control over the incremental innovation process that enables them to bring in their ideas.

\section{The case with the lowest WPI score}

This school PL-EDUC-INFO-SCHOOL-S [Poland-education-informatics-school organization] was established in 1996 in Poland. The school developed and implemented two IT systems. The first integrates information processing and communication procedures and facilitates communication among the institution, students and employees. The second is an access control system with integrated monitoring. Administrative staff has been trained to work with these systems. Many of the functionalities in these systems were suggested by employees.

The implementation of the two systems has brought benefits for employees, students and for the school: transparency has improved and there is a large reduction of administrative burden. Students can have direct and remote contact with the school and access to administrative processes and educational resources. The image of the school improved.

\section{Cases that distinguish between actionable and less actionable information for WPI}

In order to expand on the criterion of providing actionable information for WPI, we will present a case that provides information that is actionable and one that could do better in that respect (see Table 3). As an example of a case that presents highly actionable information, we chose the case of a Danish school. Firstly, the narrative describes the stakeholders involved and the actions that have been taken in terms of co-opting them: joint training sessions, setting common goals, etc. Secondly, the organizational principle for the design of autonomous teams is made explicit, namely, to create autonomous teams, each entirely responsible for educating one group of students. Of course, this is specific for a school, but on a higher level of abstraction, one can state that there was a change from a disciplinary- or functional-oriented to a clientoriented work organization. This principle can be transferred to any other work situation; therefore, it can be called actionable.

As a contrast, we briefly present the case of a Lithuanian manufacturer that has implemented highly substantial WPI practices, but could have done better in providing actionable information about them. From the description, it is not entirely clear how the work organization has been reformed to allow the teams to function as relatively independent self-managing teams. In addition, a more thorough explanation regarding the implemented procedures and the manner

${ }^{5}$ The indicators $S$ and $L$ stand for Small $=50-250$ and Large $=>250$ employees.

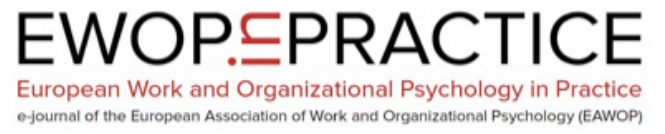




\title{
in which flex-time helps self-management would have improved the actionability of this
} information.

\section{Table 3. Two cases showing more or less actionable information about WPI practices}

\begin{abstract}
A case study with actionable information
The Danish municipal primary and lower secondary school [DK-EDUC-SCHOOL-S] has 90 employees and 700 students. Following a merger between different schools, the implementation of several educational reforms, a conflict with the unions about the payment of hours for preparation, and given the lowest influx of pupils in the municipality, it was deemed important to create a more exciting and innovative school. Workplace innovation was expected to help. To this end, the following WPI practices were implemented: 1. partnerships with stakeholders were established, 2. autonomous and interdisciplinary teams were introduced, 3. discussion forums were established.

At the start of the change project, partnerships between management, employees and (union) representatives were established to support dialogue, to enhance trust in management, to formulate common goals, and to ensure that all stakeholders were involved as partners in the change process. The creation of autonomous teams responsible for the education of an entire group of students was a structural and radical intervention. Teachers who used to be responsible only for teaching a specific subject were now made responsible for the education of a group of pupils, together with colleagues from other disciplines. Changes were discussed in a number of forums with both direct and indirect (representatives from the union) employee participation.

Many teachers appreciate the changes, although some still struggle with the fact that they cannot just teach 'their own' subject. All stakeholders have learned that, in the beginning, autonomous teams might need a framework that clarifies and delimits their areas of responsibility for action and decisions. Union representatives appreciate that it is easier for employees to get a fair share of the exciting subjects; hence, jobs have become more challenging for all employees. In the period these practices were implemented the school has also increased the student influx. The school expects to become more sustainable given that employee competences and ideas are utilized better in coping with changes.
\end{abstract}

\section{A case study that could do better in providing actionable information}

LT-MANU-RESPIR-L [Lithuania-Manufacturing-making respiratory products] is Europe's leading designer, manufacturer and supplier of a wide range of medical devices for respiratory support. The factory in Lithuania is the main production and scientific research site, part of an international group headquartered in the UK. The company employs over 1700 people in Lithuania.

The company has implemented the following WPI practices: 1. self-managing teams, 2. flexible working times, 3. (electronic) post-boxes to submit ideas, 4 . several concrete measures to improve organizational and personal learning and development.

Regarding the self-managing teams the mini case states that 'Now, the teams at the production lines are more responsible for planning (especially production time management), quality and other aspects of the production process. (Lithuania_Minicase_Intersurgical, p 1/3). The reader can imagine that there is some impact on the way tasks and responsibilities in the primary process are divided, but it is not clear how the new work organization is designed.

The case also states that working times can be arranged in a flexible way, so that employees have the opportunity to balance their work and private duties. However, the narrative does not clarify what "flexible ways" means, therefore, the information is not actionable.

Regarding the implemented idea-management practices, the case states that there is a review and a feasibility assessment of the submitted ideas. In addition, to develop the promising ideas 'responsible people are assigned to organise the implementation process' (Ibidem p 2/3). More information regarding the participation of the involved employees would have improved the actionability of this information.

Regarding training and development opportunities, collective training sessions take place each year. Individual training plans - supported by an electronic Learning Management Information System - are drawn up and implemented. Internal career opportunities are offered and supported, and much is done to stimulate learning that helps to adopt new technology. The learning and development practices are very well described and, therefore, can be transferred.

\section{Inspiring WPI cases}

For a case to serve as good example the case study should not only provide actionable information, but it should also be inspiring for various groups who want to learn from it.

\section{EWOP.PRACTICE




\section{A case that inspires by its narrative}

The German company DE-AGRO-PETFOOD-S [Germany-Agriculture-food for pets] is part of a holding and produces pet food. A few years ago, the company had to go through a complete upheaval in order to stay competitive. The whole production process was modernised by introducing machines instead of craft-based production. The new production lines required new employee competencies. Employees were educated and trained to take over every task in the manufacturing process. Moreover, some unskilled workers were trained to do production jobs - every employee had the chance to upskill and take over a skilled worker's task. Thus, former unskilled workers were trained in robotics and are now machine operators. At the request of employee representatives and the works council, every employee was given the opportunity to develop and to implement a training and career plan, which led to more qualified employees taking over more demanding jobs.

In addition, workers at the production site have leeway to organise their work as long as they meet the production deadlines given by the customers. For example, they can decide themselves to take a break, to have a meeting, or to watch a football championship game as long as they fulfil the production targets.

All these measures helped the company stay competitive. Employees like the production flexibility and the chance to improve their skills and competences as well as their new jobs.

\section{A case many different stakeholders can identify with}

IE-MANU-PHARMA-S [Ireland-Manufacturing-Pharmaceutic] is a leading manufacturer of pharmacy products mainly for the treatment of angina pectoris and related conditions. The site in Ireland was bought by a Belgian company in 2007, and there are 124 people working here.

Since 2012 the emphasis has been on integrating this plant within the larger group. This was supported by the arrival of the new HR Director who focused on strengthening employee engagement, collaboration amongst employees, creating a partnership with the principal trade union and introducing a culture of continuous improvement.

The WPI practices that were implemented are: 1 . systematic follow up of the engagement survey, 2. effective management culture, 3 . workplace partnership and 4. embedding quality and compliance.

Of these practices, the workplace partnership is the one that illustrates the important role employees and union representatives have played in the change process and the one that employees and unions can identify with. In this respect, the mini case states: "During the period of restructuring and its aftermath issues were brought formally to management by union representatives on a regular basis. In time a sense of mutual trust and understanding developed [...] Management is increasingly proactive, finding opportunities to discuss emerging issues with the union official at an early stage." (Minicase-IE-UCB, p. 2/3).

The HR manager ascribes results such as time efficiency, productivity, improved communication, improved decision making to this partnership and to the proactive discussion with union representatives about emerging issues, thus avoiding conflicts and promoting engagement at all levels.

Internal career opportunities are offered and supported, and much is done to stimulate learning that helps to adopt new technology. The learning and development practices are very well described and, therefore, can be transferred.

\section{$A$ case that can provide identification via region and sector}

This British company UK-MANU-BATH-L [United Kingdom-Manufacturing-Sanitary products] is a good example for both the North West European region and the manufacturing sector. The company was founded in 1977 in Birmingham (UK) as a family-owned business. It is now a leading supplier of showers, taps and bathrooms in the UK with exports to Europe and Russia.

Continuous improvement ( $\mathrm{Cl}$ or Kaizen) is at the heart of the company's strategy. The company's strategy is very much directed at operational excellence and innovation to meet customer's needs. This is practised by engaging all employees and stimulating them to participate in the continuous improvement. The Chief Executive points out that 'all employees have two duties: to develop themselves and to change and develop their roles' (Minicase-UK-Bristan, $p$. $1 / 3$ ). Teams are empowered to address issues from customers directly, working within boundaries set to provide room for entrepreneurial behaviour. Moreover, everyone in the warehouse is involved in the integration of technology for 'Just in time' with their team working practices.

The company does the best it can to use the talents and ideas of all employees in cross-functional project teams, in self-managing teams, in an Employee Forum and 4 to 6 Kaizen events per year.

In Table 4 above we present three cases that inspire by their narrative. We chose the narrative about the German pet food company because it gets across the positive feeling, or 'the buzz' (Totterdill \& Exton, 2014, p. 16), deriving from a complete renewal of old fashioned production processes and shows that employees and managers are excited about the future and progress.

\section{EWOP.PRACTICE


The Irish pharmaceutical company was selected because it provides us with an example that many stakeholders can identify with, especially employees and union representatives. All the workplace innovation practices are embedded in a workplace partnership between management, employees and trade union representatives.

In the case of the British bathroom equipment producer many elements of Lean production theory are recognizable, especially the notion of continuous improvement (KAIZEN). Practices from this management theory are popular in Western European manufacturing. However, Lean Production is applied in very different ways. Oftentimes it is merely a top-down measure to realize operational excellence and employee involvement only goes as far as needed to reach that goal. In this case, however, elements of Lean Production are used to structurally and culturally empower and enable employees to participate in organizational change and renewal in order to improve the quality of working life and organizational performance, that is, WPI. Therefore, this highly substantial case can be a very inspiring example for many Western European manufacturing companies.

\section{Cases that are good examples of WPI}

As we have argued before, cases that are good examples of WPI, have implemented highly substantial WPI practices, provide actionable information and are inspiring. Out of the 16 Eurofound cases that were considered to have implemented highly substantial WPI practices, we have selected three cases that fulfil all of these criteria and that can be used as good examples in a discussion about how to realize WPI in practice (see Table 5). Specifically, we chose to focus on these three because of the following reasons.

The Spanish paper product manufacturer implemented a wide range of structural and cultural measures, supported by HR practices. Most practices in this case are described in an actionable way. The case is inspiring since the story of this company makes the reader believe that it will succeed in surviving a very complicated and threatening market by mobilizing and unifying the competences, ideas and engagement of many stakeholders in the region.

Moreover, we deem this a case with which different stakeholders can identify. In short, the case shows that the whole change process is carefully orchestrated by taking into account the interests of a diverse group of stakeholders.

The case of the Danish museum was seen as an interesting bundle of structural, cultural and 'traditional' HR practices. The information about the WPI practices is actionable as it shows how seeking for a common goal and trusting social dialogue can lead to WPI. The reader can learn to trust that teams - supported by training - can find the best way to organise their work to contribute to a shared goal. Given that the museum did this and succeeded can be inspiring for others and it can lead to identification for managers, employees and union representatives.

The case of the Dutch publishing company provides actionable information. It describes how salesmen's and journalists' jobs were enlarged and enriched in a more client- or theme-oriented organizational structure. This case inspires because one feels that local management and employees have fought hard for the survival of an independent regional newspaper within the framework of being owned by a foreign company with different business ideas. Their success can be attributed to giving employees more leeway and more autonomy. People working in companies that need to search for new earning opportunities and a (partly) new business model will certainly be able to identify with this case. And many readers will recognize and identify with the employees of the media group struggling with foreign investment companies executing their own agenda. 


\section{Table 5. Three cases that are good examples of WPI practices}

\section{ES-MANU-PAPER-S [Spain-manufacturing-paper products]}

This company is a paper product producer with a total workforce of about 200 employees. The majority are men working on production-related tasks. This company has implemented a number of WPI practices over the last few years. 1. The frame for these practices is provided by good social dialogue between management, employees and three active regional trade unions. Management provides transparent information and consults employees regarding important decisions early. 2 . The common goals that facilitate this dialogue are a shared concern about the sustainability of the company (an important employer in the region) and the quality of work. 3. In terms of HR measures, there is a collective agreement that guarantees high salaries, a 35 working-hour and no overtime working is allowed. 4. The production is done in self-steering teams "that enjoy a certain degree of autonomy in the way their human resources are organized" (ES Minicase, Company X, p2/2). 5. The multi-skilling of the workers is stimulated by a "sliding work organization system" (ibidem, p. 2/2). Employees are encouraged to take up activities that are part of a job higher in rank and in different production lines. 6 . Employee representatives have suggested using biological calendars to schedule production in a way that allows satisfying the needs for rest and sleep. 7. Employee representatives participate in the process of internal reflection on new business opportunities. 8 . In the sphere of human resources management, the company is paying much attention to health and safety risk prevention, by providing information and training courses.

The stakeholders show enthusiasm about the (expected) results. According to management, the WPI practices have led to a good employment climate, skilled, well-motivated and committed staff, and a good use of the innovative ideas of the employees. This in turn, has resulted in improved economic and financial company performance. The employees think this company is a good employer and that the employment conditions are excellent. The unions especially appreciate the actions that contribute to the net creation of employment in the region, such as the financial results and the 35 hour-working week with no overtime.

\section{DK-ART-MUSEUM-S [Denmark-Art \& Leisure sector-Museum]}

This organization is a museum with 140 employees divided over nine worksites in a larger Danish municipality. During the last years, the pressure to compete with other attractions (cinemas, amusement parks) has increased, and the museum realises the importance of employee involvement to create appealing guest experiences. This case study focussed on WPI practices that concerned two professional groups: hosts and craftsmen in the open-air museum. The implemented WPI practices were: 1. autonomous team work for the craftsmen, 2. a good hosting project, and 3. partnership with unions.

Funen Village is a living workplace, where guests watch craftsmen work on the antique buildings. Previously, the craftsmen's' work centred around maintenance with eighty percent of their working day being spent on following a mandated plan. Now, the teams autonomously organise the task sequence, the planning, work mode, duty roster and budget. They have the opportunity to plan their work in such a way that they can perform jobs that are interesting for the guests to see, during business hours. They also have more time to talk with visitors about their craft.

The museum hosts sell tickets and make sure that the exhibitions function. The hosting project was based on experiences from other types of businesses (e.g., Legoland, the famous Danish theme park) on how to create an exciting guest experience. The museum hosts were trained and, subsequently, formulated new work codes on, for instance, how to greet the guests and how to inspire the guests to explore the exhibitions. They received a book about good hosting experiences providing many tools which changed their jobs. The partnership took shape in a joint committee with union representatives, Occupational Health \& Safety representatives and management representatives (based on a regional framework).

Management, representatives and employees agree that the new practices provide greater job satisfaction for employees while simultaneously enabling the company to provide better service. The focus, in general, has shifted from a narrow focus on specific disciplines to a customer focus.

\section{NL-INFO-NEWS-L [Netherlands-Information-Newspaper]}

This company is the publisher of a regional newspaper in the Netherlands with about 300 employees. For more than a decade, the company's existence is being threatened by diminishing earnings from selling subscriptions and advertisements and by the development of new information technologies. In addition, there was a stream of changing international owners and management with different strategies.

By engaging in coalitions supported or initiated by the Works Council and employees, the local management succeeded in implementing WPI practices with the aim of mobilizing employee talents and finding new earning models. These practices were: 1. upskilling and redesigning the jobs of the advertising salespeople into account managers, 2. restructuring the editorial department and redesigning the journalists' jobs, 3. dialogue between employees and CEO regarding ideas for business improvement, 4 . four cross-functional teams that each develop a new idea, 5. cooperation with external partners, such as a university for applied science and a broadcasting company.

The role and the targets of the salespeople have changed completely: instead of selling advertisements by phone, they now have to build a relationship with the clients and to consult them on how to best reach their intended customers. The editorial work used to be organized along regions in the province, producing daily news messages. Given that nowadays this information is more easily distributed by social media, now the value added of a news outlet is to produce more background stories and in-depth studies. Therefore, most of the journalists were placed in the Research department and were organized into specific Theme groups (e.g., Health, Sports, Education). This new way of organizing in multifunctional theme groups provides opportunities for journalists to cooperate with account managers in writing targeted articles.

Management-employee dialogue resulting in cross-functional teams developing promising ideas are familiar practices in other companies as well. However, what is striking here is the thoughtful way in which they organised this. For instance, team members work full-time in these cross-functional teams for a certain period of time and are thoroughly trained and coached to do the job.

The results for the company seem positive. The newspaper is still on the market and is investing in new earning opportunities. The employees have more challenging jobs, have better career prospects and the feeling of being heard and taken seriously. 
Table 6 below shows that these three cases meet all the criteria and can be used as good examples.

Table 6. Summarizing the three cases that are good examples of WPI

\begin{tabular}{|c|c|c|c|}
\hline & ES-MANU-PAPER-S & DK-ART-MUSEUM-S & NL-INFO-NEWS-L \\
\hline $\begin{array}{l}\text { highly substantial } \\
\text { case }\end{array}$ & Yes, score: $7.5^{\star}$ & Yes, score: 7.7 & Yes, score: 8 \\
\hline $\begin{array}{l}+ \\
\text { reported case } \\
\text { study/actionable } \\
\text { information }\end{array}$ & $\begin{array}{l}\text { Mini-case } \\
\text { Information could be } \\
\text { more actionable }\end{array}$ & $\begin{array}{l}\text { Mini-case, including } \\
\text { actionable information } \\
\text { about redesign of } 2 \text { jobs } \\
\text { and team working }\end{array}$ & $\begin{array}{l}\text { Mini-case, including } \\
\text { actionable information about } \\
\text { redesign of jobs and } \\
\text { organizational structure, } \\
\text { employee groups for business } \\
\text { development }\end{array}$ \\
\hline $\begin{array}{l}+ \\
\text { inspiring } \\
+ \text { possibilities for } \\
\text { identification }\end{array}$ & $\begin{array}{l}\text { Yes, by mobilizing many } \\
\text { stakeholders in the region } \\
\text { to retain employment }\end{array}$ & $\begin{array}{l}\text { Yes, the image of the } \\
\text { museum modernized; } \\
\text { Managers and unions can } \\
\text { identify because of } \\
\text { partnership model }\end{array}$ & $\begin{array}{l}\text { Yes, for companies and } \\
\text { stakeholders that need to } \\
\text { mobilize all talents to develop } \\
\text { new business opportunities. } \\
\text { Employee representatives can } \\
\text { be inspired by the role of the } \\
\text { works council here. }\end{array}$ \\
\hline
\end{tabular}

Note: * - scores given by the Eurofound experts.

\section{To conclude}

Many practitioners find it problematic to define workplace innovation. The well-known definitions hardly provide any actionable information. In this contribution, we have argued that, for practitioners, examples of cases describing best WPI practices can provide value added to purely theoretical definitions of WPI. Therefore, we tried to answer the question: What makes a case a good example of WPI practice?

In this article, we proposed the following criteria. First, the company that serves as a case should have implemented good, highly substantial WPI practices in a participative way. Those practices must have led to or promise to lead to improved company performance and improved quality of work for the employees involved. Second, the case description needs to provide actionable information about the WPI practices implemented. That is, it provides information on what has been changed in the structure, the culture and in supporting HR practices and how that has been done. Third, the case has to be inspiring; that means that the narrative really gets across the story of the change in the organizational structure, culture, climate and behaviour of management and employees, as well as, their enthusiasm about the (expected) results. An inspiring case also provides the opportunity for diverse groups in other organizations to identify with it. That is, others can recognize and identify with the kind of work, the sector and/or the cultural context.

To illustrate these criteria, we used the cases from the recent Eurofound study. First, we focused on cases that were identified by experts in the Eurofound study as having implemented highly substantial WPI practices as well as less substantial WPI practices. Subsequently, we focused our attention on the sample of 16 highly substantial cases in the Eurofound study, given that this is a sine-qua-non for a case to be able to provide any useful information on WPI best practices. Within these 16 mini-cases we found and described some that provided actionable information and some that could do better on that criterion. Moreover, we found cases that are inspiring because the narrative not only presents what has been changed in the company and how it has been done, but also gets across 'the buzz' generated. Finally, we 
described three cases that embody all three criteria and can be used by practitioners as examples of best practices for WPI.

Some take-away messages for practitioners are the following: A case that is a good example of WPI practice can help clarify what managers and employees might change in the structure and culture of an organization and how to do that. Therefore, practitioners should consider finding cases that have been rated by experts as having implemented effective WPI practices.

Moreover, these cases should have an inspiring narrative that describes the practices and the change process in an actionable way. Practitioners might also want to consider in how far people in their organization would be able to identify with that case. Depending on the situation, that might be the sector, the region or a specific approach, such as a dialogue.

Surely, this is not a fool-proof recipe and we advise practitioners to be flexible in their approach. Surprisingly, a case from a service sector might inspire employees from a manufacturing company. Practitioners should also keep in mind that a case description is not a handbook for how to implement workplace innovation. The best-practices-approach has its own general limitations, and, practitioners should be prepared to be flexible and adapt any best practices to their own context. In this sense, a good case example can be a source of information for finding practical solutions for specific problems in an organization as well as provide inspiration for discovering new perspectives.

\section{References}

Argyris, C. (1996). Actionable knowledge: Design causality in the service of consequential theory. The Journal of Applied Behavioral Science, 32(4), 390-406.

Dhondt, S., Preenen, P., Oeij, P., Corral, A., Isusi, I., Totterdill, P., \& Karanika-Murray, M. (2014). European Company Survey: Construction of the Workplace Innovation Index and Selection of Companies. Leiden: TNO.

Dortmund/Brussels Position Paper on Workplace Innovation, 26 June 2012. Retrieved from: http://www.kennisbanksocialeinnovatie.nl/nl/kennis/kennisbank/workplace-innovation-as-socialinnovation/1009/download/dortmund-brussels-position-paper-12th-june-2012/1980

Gabriel, Y. (2013). Researchers as storytellers: Storytelling in organizational research. In M. Gotti \& C. S. Guinda (Eds.). Narratives in Academic and Professional Genres (pp. 105-122). Bern: Peter Lang.

Eurofound (2015). Kankaraš, M., \& van Houten, G., Third European Company Survey 2013 - Overview report: Workplace practices - Patterns, performance and well-being, Publications Office of the European Union, Luxembourg.

European Commission (2014). Kesselring, A., Blasy, C., \& Scoppetta, A. Workplace Innovation: Concepts and Indicators. Brussels: European Commission, DG for Enterprise and Industry.

Oeij, P., Žiauberytè-Jakštienè, R., Dhondt, S., Corral, A., Totterdill, P., \& Preenen, P. (2015a). Third European Company Survey: Workplace innovation in European companies. Study commissioned by Eurofound. Luxemburg: Publication Office of the European Union.

Oeij, P., Žiauberytè-Jakštienè, R., Dhondt, S., Corral, A., Totterdill, P., \& Preenen, P. (2015b). Workplace Innovation in European companies. Technical annex. Dublin: Eurofound.

Pot, F. D. (2011). Workplace innovation for better jobs and performance. International Journal of Productivity and Performance Management, 64(4) 404-415.

Pot, F. D., Dhondt, S., \& Oeij, P. R. A. (2012), Social innovation of work and employment. In H-W. Franz and J. Hochgerner (Eds.), Challenge Social Innovation (pp. 261-274). Berlin: Springer.

Ramstad, E. (2009). Promoting performance and the quality of working life simultaneously. International Journal of Productivity and Performance Management, 58(5), 423-436.

Rappaport, J. (1995). Empowerment meets narrative: Listening to stories and creating settings. American Journal of Community Psychology, 23(5), 795-807.

Totterdill, P., \& Exton, R. (2014). Defining workplace innovation: The Fifth Element. Strategic Direction, Vol. $30(9), 12-16$. 